these, winning prestigious and highly competitive individual-investigator grants for basic-research projects. More than 30 were awarded ERC funding in its sixth Starting Grant competition in July, for example. The country is second only to Switzerland in its number of ERC grantees per capita (see 'Punching above its weight').

"We are watching with a great sadness even horror - at the mixing of politics into science," says Geiger, himself a holder of an ERC grant. "There is a lot to lose."

In a bid to break the deadlock, another round of negotiations took place in Brussels last week. No concrete progress was made, but Michael Jennings, a European Commission spokesman, described the day-long talks as "constructive and open", with both sides hoping to find a resolution before Horizon 2020 launches on 1 January.

He added that the restriction of Horizon 2020 funding to the non-occupied territories would have little impact on Israeli scientists, almost all of whom work within pre-1967 borders. Only one beneficiary of FP7 grants, cosmetics company Ahava Dead Sea Laboratories in Mitzpe Shalem in the West Bank, would have been ineligible had the guidelines been in place for FP7, and currently only about $€ 1.5$ million flows into the occupied territories. Both sides are considering how the guidelines could be implemented in a mutually acceptable manner, and will meet again in a few weeks, Jennings said.

Ruth Arnon, president of the Israel Academy of Sciences and Humanities in Jerusalem, wrote to Prime Minister Benjamin Netanyahu last month, warning him that Israel's failure to join Horizon 2020 would damage the country's science irreversibly. Others have warned that it is up to the scientific community to save the programme. "Whatever their individual political views, Israeli scientists need to come together to shout their concerns about a future without Horizon 2020 - but they have shied away from this," says Yadin Dudai, a neuroscientist at the Weizmann Institute.

Dudai is especially concerned about Israel's future involvement in the Human Brain Project, an 80-partner EU flagship programme that aims to unlock the mysteries of the mind and develop treatments for brain diseases. The project is currently in a ramp-up phase that is being partially funded by FP7; eight of its principal investigators are Israeli, including Dudai.

Gal Richter-Levin, a neuroscientist at the University of Haifa, says it is good for scientists to rub shoulders with their EU counterparts. "When we collaborate with colleagues in other countries, we have the opportunity to be criticized by them over a beer in the evenings," he says. "This helps us to form our political views - and this is also a reason for not abandoning scientific collaborations." -

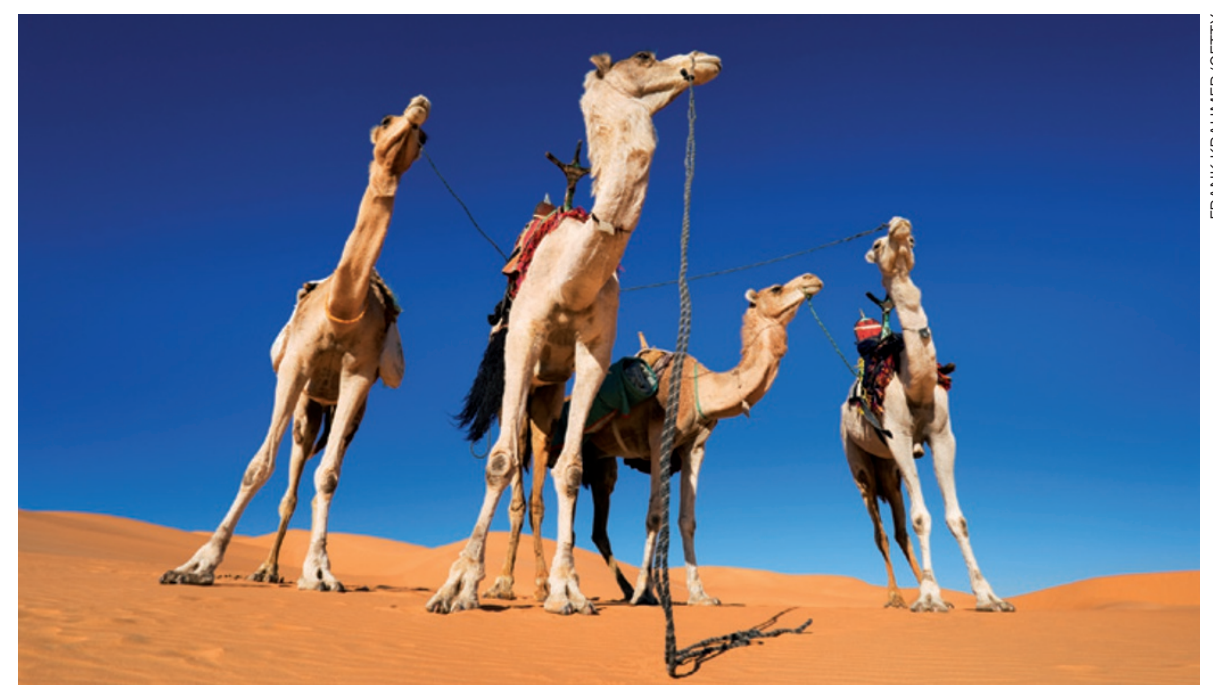

Possible infection with the MERS coronavirus, or a closely related virus, has been detected in camels.

VIROLOGY

\title{
Progress stalled on coronavirus
}

\section{Lack of in-depth studies hampers efforts to identify source.}

\section{BY DECLAN BUTLER}

A year on from the first reported human case of infection with Middle East respiratory syndrome coronavirus (MERS-CoV), the world still has few answers to the most pressing question from a publichealth perspective: what is the source of the steady stream of new cases? Only with this information can the outbreak be controlled.

There have so far been 114 confirmed cases of MERS-CoV infection, including 54 deaths, with another 34 suspected cases (see 'Catching on'). All originated in the Arabian Peninsula, with most in Saudi Arabia and others in Jordan, Qatar and the United Arab Emirates (UAE). Imported cases have occurred in the United Kingdom, France, Italy and Tunisia. The virus is thought to be an animal virus that sporadically jumps to people - there are no signs yet that it can spread easily between humans, although limited spread between people in close contact has been seen.

But a lack of epidemiological studies means that the source of the virus is still unknown. This is "absolutely unacceptable", says Michael Osterholm, head of the University of Minnesota's Center for Infectious Disease Research and Policy in Minneapolis. Affected countries have to some extent lacked a sense of urgency, agrees Jean-Claude Manuguerra, head of the Laboratory for Urgent Response to Biological Threats at the Pasteur Institute in Paris. They have also tended to consider it a sovereign issue that is the business of national authorities, not outsiders, he adds.

Manuguerra was one of 13 international health experts invited by the Saudi Arabian government and the World Health Organization (WHO) in Geneva, Switzerland, to visit the country in June as part of a joint mission to assess the situation and recommend measures to control the outbreak. He contrasts the lack of progress on MERS epidemiology with China's rapid and robust response following the report in March of the first human cases of a new H7N9 avian influenza virus (see Nature 496, 397 ; 2013), which quickly identified live-bird markets as the main route of human infections and moved swiftly to shut them down.

To identify a source of infection, patients must be questioned in detail about their recent activities, such as whether they visited animal markets or farms, or ate certain foods, to find patterns and leads for investigation. But the joint Saudi-WHO mission concluded that such work has not been detailed enough to accomplish this.

Also insufficient, the mission said, were efforts to look for the virus in animal populations, which would enable transmission routes to humans to be shut down. Bats are likely to have been the original source: the genome sequence of the MERS virus is closest to that of 


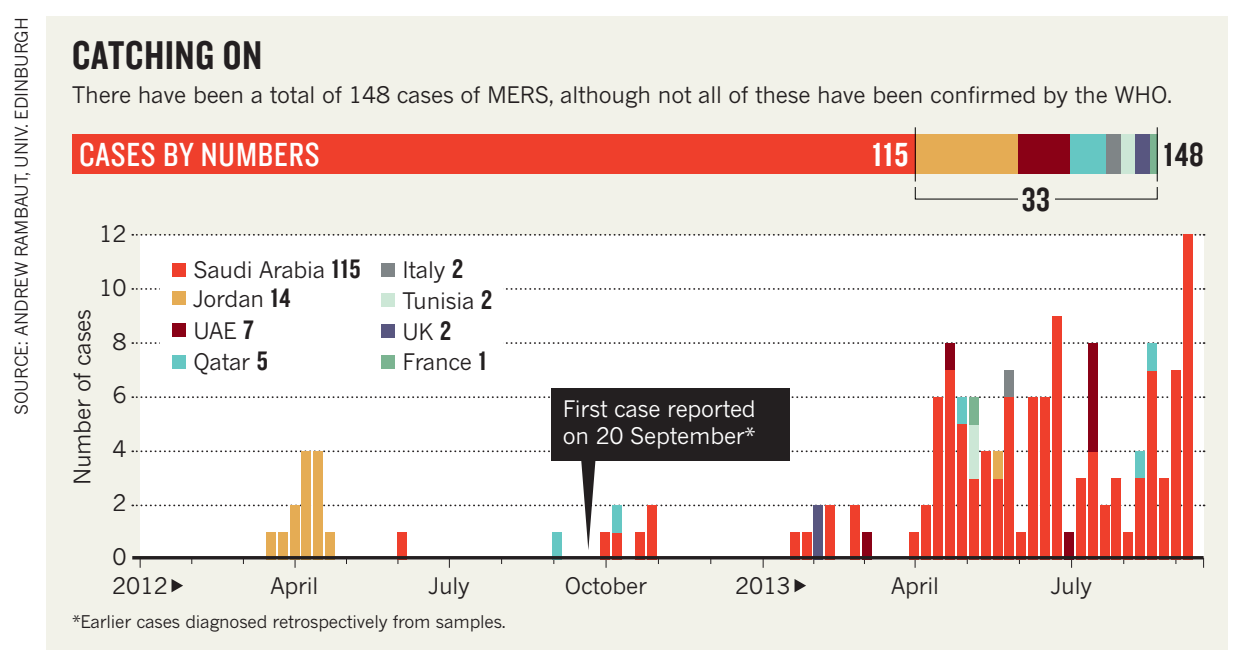

other bat coronaviruses. Since this discovery, Saudi Arabia has twice invited a team led by Ian Lipkin, a virologist at Columbia University in New York, to sample bat tissue and faeces, and in August the team published a partial sequence that seems to match that of MERS ${ }^{1}$ (see Nature http://doi.org/ntk; 2013).

But direct contact with bats is unlikely to explain the human cases, and scientists suspect that the virus has infected other animals that are more likely to come into contact with people. Some say they are baffled that affected countries have not carried out large-scale sampling of animals to look for the virus. Ziad Memish, Saudi Arabia's deputy minister of health, says that his country has been waiting for advice about testing from the Rome-based United Nations Food and Agriculture Organization (FAO) and the World Organisation for Animal Health in Paris. officer, says that its first expert mission to assess possible animal sources left last weekend for Saudi Arabia and the UAE. There will be several
Juan Lubroth, the FAO's chief veterinary more, he adds, and the FAO hopes to work with national authorities to start epidemiological studies within months.

A tantalizing clue to a possible animal source comes from two studies on camels ${ }^{2,3}$. Both found antibodies to MERS or a closely related virus in camels in neighbouring countries to those affected, indicating past infection. Neither found live virus in the animals, however.

"It is possible that such a virus is ubiquitous, but from time to time is undergoing crucial mutations that allow limited cross-species jumps from the intermediate host to humans," says Malik Peiris, a virologist at the University of Hong Kong and a co-author of one of the studies. That was the scenario with the exotic coronavirus SARS that emerged in Hong Kong in late 2002 and evolved to become a virus that spread easily between humans, killing almost 800 people before dying out in July 2003.

With millions soon to be on the move for the hajj, the annual pilgrimage to Mecca in midOctober, the Saudi authorities are on high alert for suspected cases of MERS, and will no doubt be hoping that MERS is not the next SARS

1. Memish, Z. A. et al. Emerg. Infect. Dis. http://dx.doi. org/10.3201/eid1911.131172 (2013).

2. Reusken, C. B. E. M. et al. Lancet Infect. Dis. http:// dx.doi.org/10.1016/S1473-3099(13)70164-6 (2013).

3. Perera, R. A. et al. Eurosurveillance 18(36), 2 (2013). 